\title{
Application of the method for prediction of the failure location and time based on monitoring of a slope using synthetic aperture radar
}

\author{
Yi-hai Zhang ${ }^{1} \cdot$ Hai-tao $\mathrm{Ma}^{1} \mathbb{D} \cdot$ Zheng-xing Yu$^{1}$
}

Received: 31 October 2020 / Accepted: 17 September 2021 / Published online: 17 October 2021

(c) The Author(s) 2021

\begin{abstract}
Synthetic aperture radar (SAR) technology has been widely used in landslide deformation monitoring in the past decade. It has the advantages of high monitoring accuracy, a wide range, and flexibility allowing all-weather continuous monitoring. The self-developed S-SAR synthetic aperture radar (slope radar) is the first completely domestic-made radar used in slope deformation monitoring equipment in China, and its performance and technical parameters are equal to or better than similar products made abroad. The characteristics of deformation data collected by S-SAR slope radar deployed in the front open pit mine are analyzed to further develop a spatio-temporal landslide prediction method which is applicable to the massive monitoring data within the monitoring range of slope radar. The intersection points of short-term moving average velocity curve and long-term moving average velocity curve of slope deformation, which are onset of acceleration (OOA) and termination of acceleration (TOA). When OOA occurs, the deformation will accelerate, and when TOA occurs, the deformation will tend to stabilize. The OOA can identify areas at risk in the monitored area before failure, so that the spatial position prediction of landslide early warning can be realized. Based on the assumptions of the inverse velocity method, a $T$ - $\log (t) \operatorname{logarithmic}$ model is established, and the updated monitoring data are corrected to approximate the time of failure, thus improving the accuracy of landslide location and time prediction. In an open-pit copper mine in Serbia, the accurate prediction of landslide location and time has been successfully applied, guaranteeing safe mining.
\end{abstract}

Keywords Slope radar monitoring - Onset of acceleration - Termination of acceleration prediction of failure time $\cdot$ Method of landslide location and time prediction

\section{Introduction}

Landslides are one of the most common natural disasters and pose a major threat to people's lives and property. Landslides are natural phenomena of soil or mountain under the action of gravity, sometimes caused by external natural factors such as rainfall, earthquakes, volcanic eruptions, and anthropogenic effects (Wu et al. 2018; Ubydul 2019). The annual global economic loss caused by landslides is about $\$ 19.8$ billion, accounting for about $17 \%$ of the annual global natural disaster losses (Haque et al. 2016). Projections that are based on the possible effects of climate change suggest

Hai-tao Ma

maht@chinasafety.ac.cn

1 China Academy of Safety Science and Technology, Beijing 100012, China that these numbers will probably increase (Gariano and Guzzetti 2016). Therefore, landslide prediction is of importance (Intrieri et al. 2012; Greco et al. 2013). In recent decades, greater scientific efforts have been made to study landslide damage predictions and to deepen the understanding of these landslide phenomena. Due to the hydrogeological environment of landslide, the complexity and diversity of formation and causative factors and the randomness, uncertainty, and non-linearity of evolution, the deformation characteristics of the landslide are very complicated, which makes landslide development a complicated process. Therefore, it is worthwhile to obtain detailed and accurate information about this process (Lacasse and Nadim 2009; Intrieri et al. 2013; Do et al. 2017; Do and Wu 2020).

Significant efforts have been made in the scientific community to deepen the understanding of the phenomenon of landslides. In the past, due to the retrospective monitoring technology, the prediction of landslides was hindered, 
especially those open-pit mine landslides, which occur rapidly. In recent years, with the development of technology, various methods of slope stability monitoring system have been developed. Particularly in remote sensing instruments based on ground, air or satellite platforms. The most commonly used remote sensing techniques for landslide monitoring are: (1) photogrammetry (Kraus et al. 1997); (2) laser rangefinder and total station surveys; (3) ground laser scanner (Teza et al. 2007); (4) radar interferometry (Massonet and Fiegl 1998); (5) global Positioning Systems (Brunner et al. 2003). Compared with photogrammetry, laser rangefinder and total station surveys, ground laser scanners or GPS, monitoring radar is a fully remote sensing technique. It provides continuous spatial coverage and is relatively insensitive to the surrounding environment for long-term overall analysis and prediction. It does not require the installation of artificial reflectors or devices on slope surfaces, thus enabling it to monitor very dangerous areas, even in places otherwise inaccessible. Radar waves penetrate bad weather such as rain, dust, and smoke to provide reliable measured data.

The concept of radar-surveying for slope stability monitoring originated from satellite technology. In the 1990s, satellite-based synthetic aperture radar (SAR) was used to detect displacements on the earth's surface using phase information in radar images (Borgeaud et al. 1994; Srivastava et al. 1996). In 2003, continuous monitoring of landslide movement was carried out on a slope in Italy using roadbed SAR interferometry. Although the results obtained show sufficient capability to detect landform movement caused by landslides, some problems remain to be solved (Tarchi et al. 2003; Pieraccini et al. 2003). In recent years, ground-based radar has been widely used in landslide monitoring and landslide prediction (Bozzano et al. 2010; Ginting et al. 2011; Dick et al. 2015; Carlà et al. 2016).

Before a landslide, macroscopic deformation and signs of failure such as surface deformation are obvious. Therefore, displacement monitoring plays an important role in predicting landslide failure in space and time. In the 1960s, Saito performed many triaxial compression laboratory experiments, and found that displacement is important in predicting time to failure. Saito $(1965 ; 1969)$ simultaneously proposed a method to predict the failure time $T_{\mathrm{f}}$ of landslides based on traditional creep theory, which divides the creep process into three stages (Fig. 1): the primary stage, secondary stage, and tertiary stage, and landslides usually occur in the tertiary stage.

Primary stage $(\mathrm{AB})$ : when the slope body is in critical equilibrium due to the influences of various factors, if it is suddenly affected by strong external factors such as engineering construction or rainfall, it will start suddenly and show obvious signs of deformation. When the external load is decreased, the deformation of slope is also reduced.

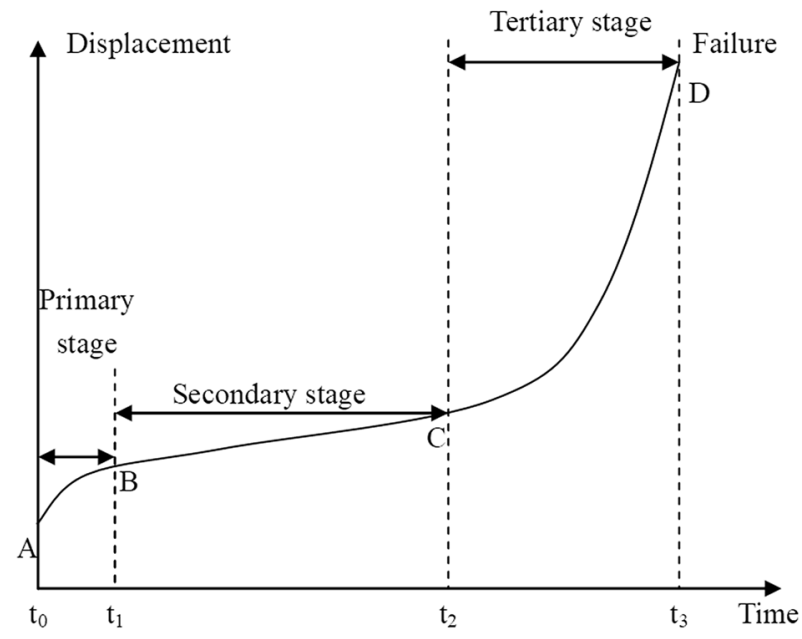

Fig. 1 Three typical stages in landslide evolution

Therefore, the initial deformation stage is the starting deformation stage of the landslide, and the curve is concave.

Secondary stage (BC): after the onset of slope deformation, the potential sliding surface gradually forms and the landslide enters a period of slow creep deformation. Although the potential sliding surface is broken gradually by shear action, and the resistance to sliding is weakened. As a result of stress adjustment, the shear resistance and sliding force of the slope are in a quasi-equilibrium state, and the deformation of the slope is characterized by constant creep. The deformation curve at this stage is quasi-linear, which will fluctuate when subject to external interference.

Tertiary stage (CD): at the end of the uniform deformation, the shear stress on the potential sliding surface reaches its peak shear strength and then slowly decreases to the residual strength. However, the sliding resistance continues to increase with the breakage of the potential sliding surface, and the sliding resistance is less (weaker) than the sliding force, and the slope begins to accelerate the deformation. The displacement curve becomes concave. From the beginning of acceleration to deformation and failure, the movement of the landslide is significantly different.

It is found that there is an accelerated deformation stage before the slope slides as evinced by the creep deformation curve of three stages before the slope sliding. Therefore, how to identify the onset of acceleration point (OOA) in the acceleration stage is important for landslide early warning and prediction. In this paper, a method is proposed to realize the automatic identification of the most dangerous area, that is, the area about to undergo accelerated deformation. Based on the improved reciprocal velocity method, a logarithmic function landslide time prediction model is proposed. A landslide event was successfully predicted in a copper mine in Serbia by applying slope radar monitoring data, which 
verified the practicability of the research content and ensured safe and efficient production in the mine.

\section{Slope monitoring S-SAR}

SAR is an advanced radar detection system developed in the late 1960s, which can achieve long-term monitoring of mine slopes. At the same time, SAR is also a high-resolution imaging radar system, with the ability to produce longrange, high-resolution images. The SAR achieves the highrange resolution by pulse compression and the high-azimuth resolution is obtained by the relative motion between the radar and the observed target. By combining the two-dimensional high-resolution images acquired at different times in the same target area, the phase difference inversion of each pixel in the image is used to obtain high-precision deformation information about the measured area. The geometric principle of SAR monitoring system is shown in Fig. 2. As shown in Fig. 3, the coordinate axes in SAR are the distance and azimuth direction of the radar image and the direction of parallel to the track is azimuth, while the direction of parallel radar waves represent the distance to target.

The S-SAR is composed of a radar subsystem, tracking subsystem, power supply and control subsystem, data storage subsystem, and control software. The radar subsystem can transmit and receive electromagnetic signals with large bandwidth rapidly; the orbit subsystem carries the radar subsystem to complete high-precision smooth linear motion and realize azimuth aperture synthesis; the power supply and control subsystem completes the whole system power supply and control task; data storage subsystem completes the rapid storage and data interaction of massive data; the

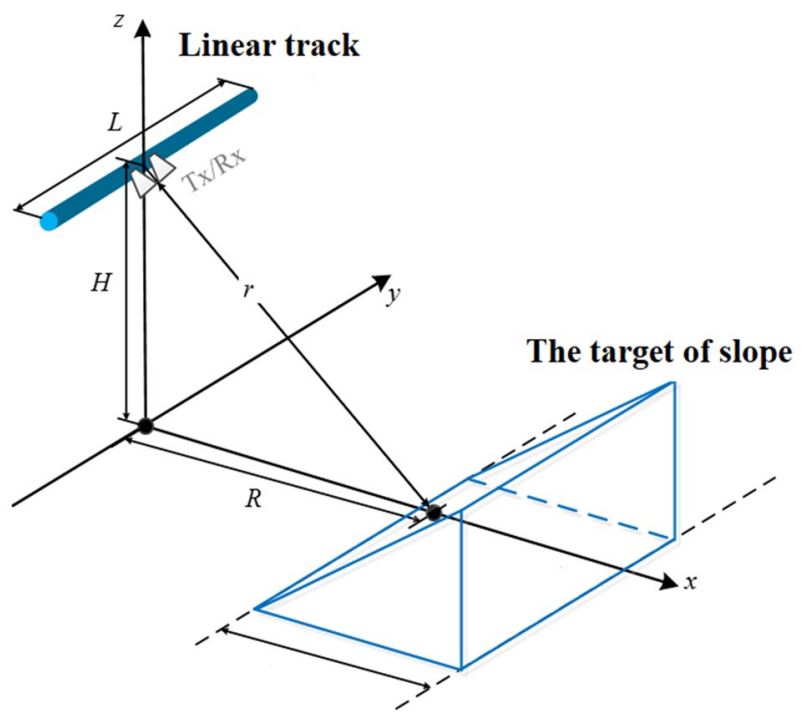

Fig. 2 Geometric model of a radar-based monitoring system

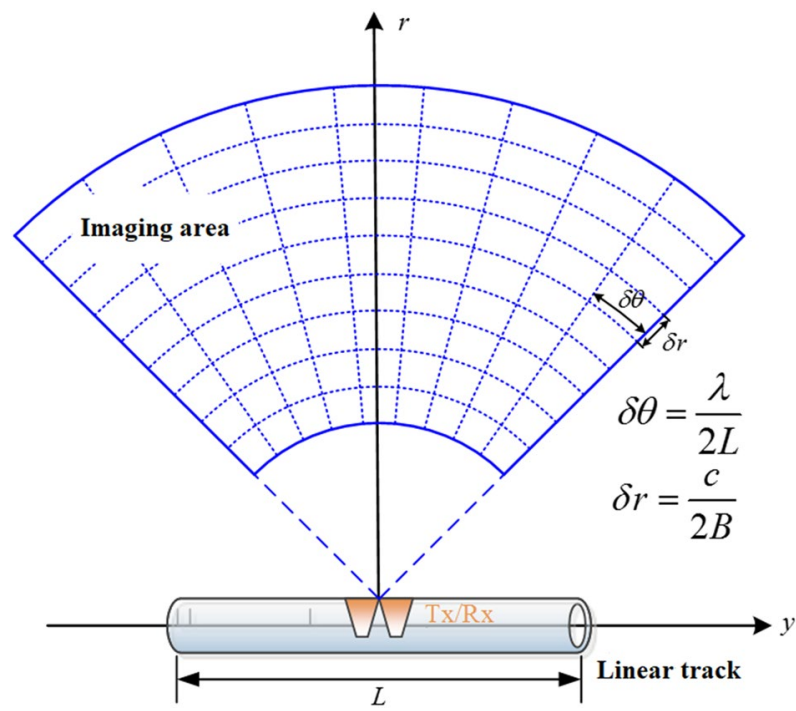

Fig. 3 Schematic diagram of the two-dimensional imaging technique

control software subsystem completes data management, echo data pre-processing, imaging processing, deformation information extraction, and deformation information analysis and warning.

S-SAR slope monitoring radar is shown in Fig. 4. At present, S-SAR slope monitoring radar performance indicators and advantages include:

(1) The microwave operating frequency is $17 \mathrm{GHz}$ and the bandwidth is $500 \mathrm{MHz}$.

(2) Measuring distances can reach $5 \mathrm{~km}$, with no need to install sensors in the monitored target area.

(The slope deformation measurement accuracy is up to $0.1 \mathrm{~mm}$ with high spatial resolution $(0.3 \mathrm{~m} \times 8.8 \mathrm{~m}$ at $1 \mathrm{~km})$.

(3) The data collection time is less than $10 \mathrm{~min}$.

(4) It can continuously cover a monitoring area of several square kilometers. By analyzing the information per-

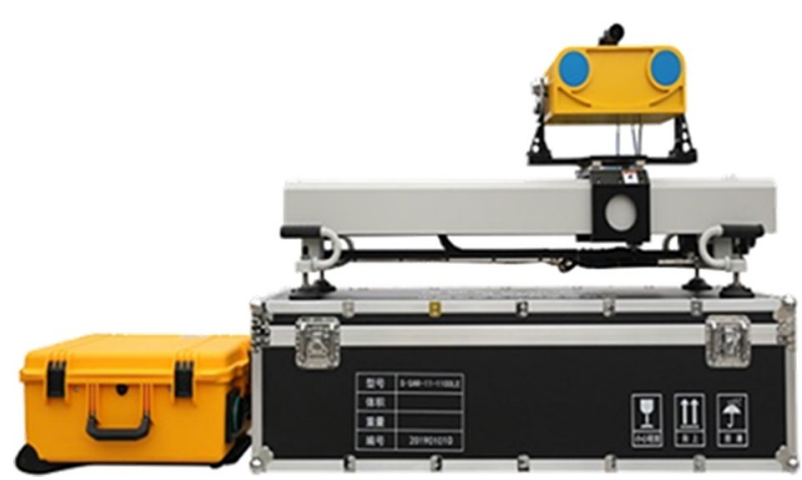

Fig. 4 S-SAR slope monitoring radar 
taining to a single pixel, the local displacement field can be obtained.

(5) It can provide continuous data collection under various severe weather conditions such as rain, wind, and fog.

The data-acquisition software is independently developed. The main interface of the acquisition software is shown in Fig. 5.

Its detailed description and working process are as follows:

(1) Project Settings Window contains the following functions: (1) server address: the address of the server to upload the collected data; (2) radar ID: S-SAR Type Synthetic Aperture Radar device identity document; (3) site ID: radar monitoring project identity document.

(2) Configuration Window contains the following functions: (1) project path: the data-acquisition storage path; (2) near range: the radar monitors the nearest range (select a value for 0-5000 m); (3) far range: the radar monitors the farthest (select a value for 0-5000 m); (4) beamwidth: radar imaging area visual range $\left(30-90^{\circ}\right)$; (5) aperture length: radar linear orbit range (usually no setting); (6) step size: radar single measurement step size and visual range of radar imaging area $\left(30-60^{\circ}\right.$ is $8 \mathrm{~mm}, 60-80^{\circ}$ is $7 \mathrm{~mm}, 80-90^{\circ}$ is $6 \mathrm{~mm}$ ); (7) averaging factor: single step collection times (usually no setting); (8) revist interval: approximately the collection cycle.

In the working process, the software will display the interferogram and two-dimensional image of the target in real time, as shown in Figs. 6 and 7.

Displacement monitoring plays an important role in predicting landslide failure time. Previously, poor monitoring technology hinders the prediction of landslide time, especially for landslides in open-pit mines, whose landslide failure times are very short. In recent years, with the development of technology, many efficient monitoring techniques are available. Ground-based radar is one of the most efficient and powerful monitoring techniques; its characteristics are highly suitable for landslide monitoring requirements. In the early 1990s, ground-based radar was initially used to measure ground displacements within a region (Massonet and Fiegl 1998). In the early 2000s, some innovations occurred in ground-based radar technology, and the first prototype of ground-based radar equipment was developed. Over the past decade, ground-based radar was extensively applied to monitor landslides, and the successful application of ground-based radar in landslide prediction has been widely studied (Bozzano et al. 2010; Ginting et al. 2011; Dick et al. 2015; Carlà et al. 2018).
Fig. 5 Interface of data-acquisition software

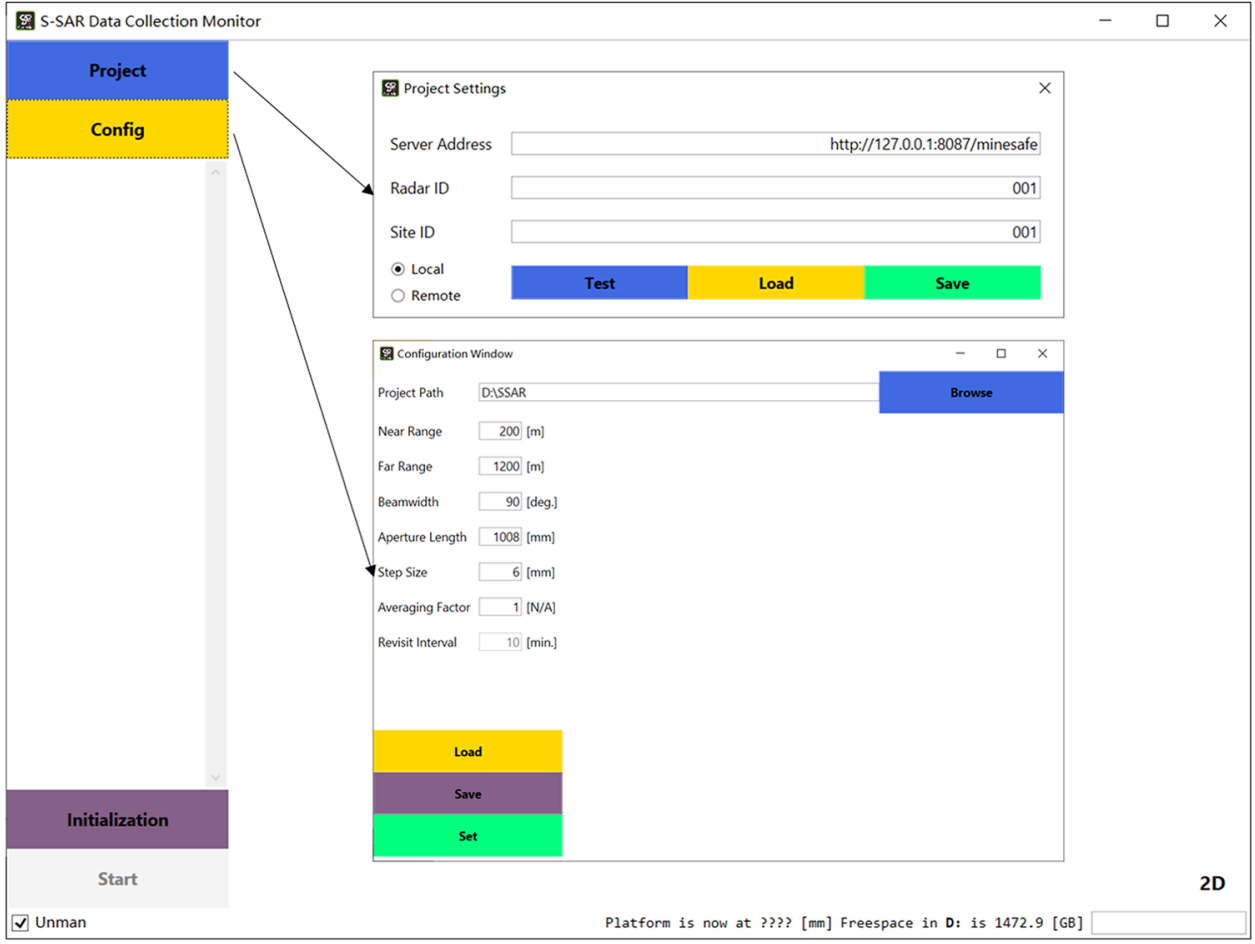


Fig. 6 Monitoring target radar interference image

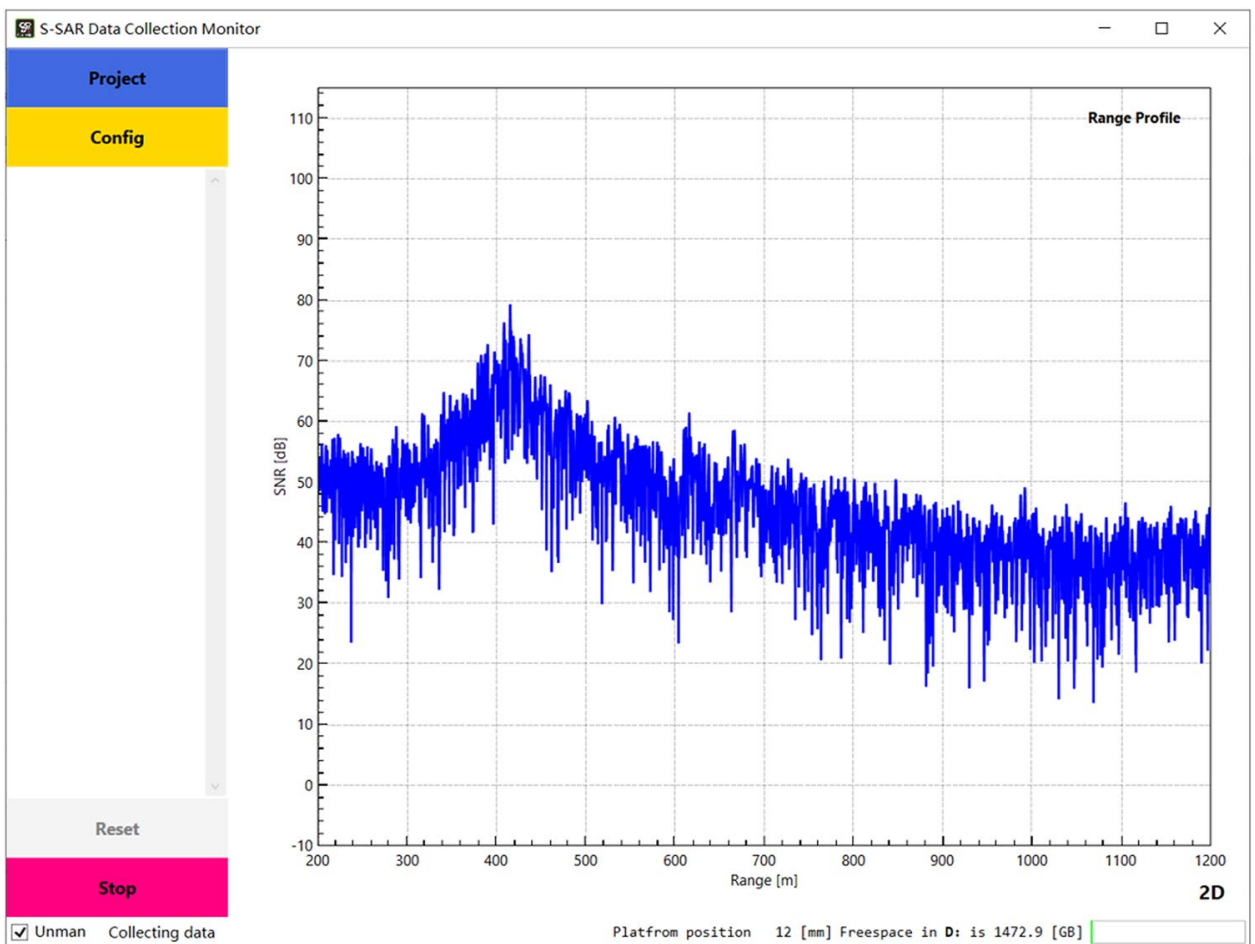

Fig. 7 Monitoring target radar two-dimensional image

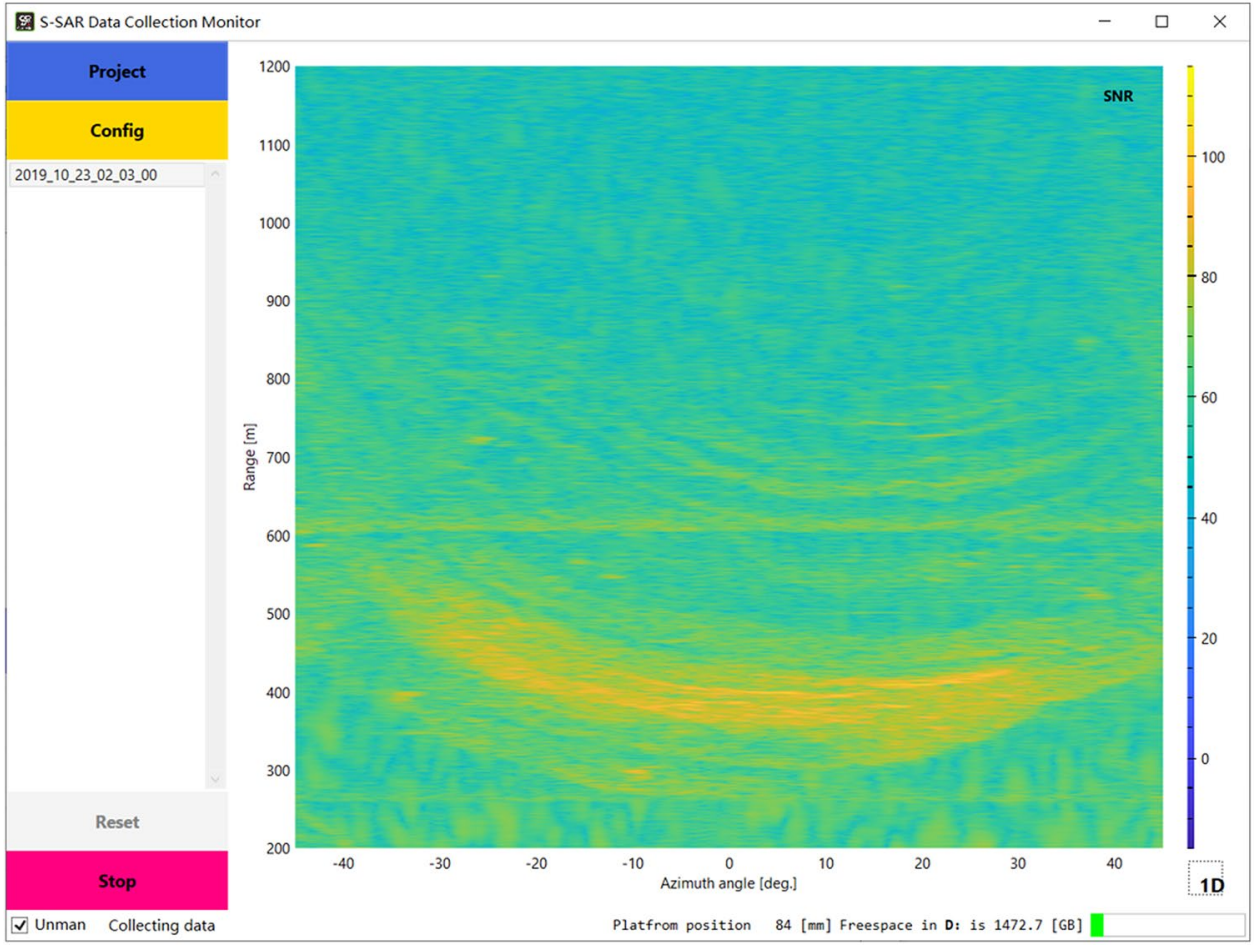

\section{A method of slope position-time prediction based on massive radar monitoring data}

Figure 8 shows that the radar calculates the shape variable of the same spatial position with the time series by untangling the phase of different time interference waves at the same pixel. Figure 9 illustrates that a slope radar cumulative displacement cloud map can reach tens of thousands or even hundreds of thousands of pixels. The displacement and deformation values of all pixels are 


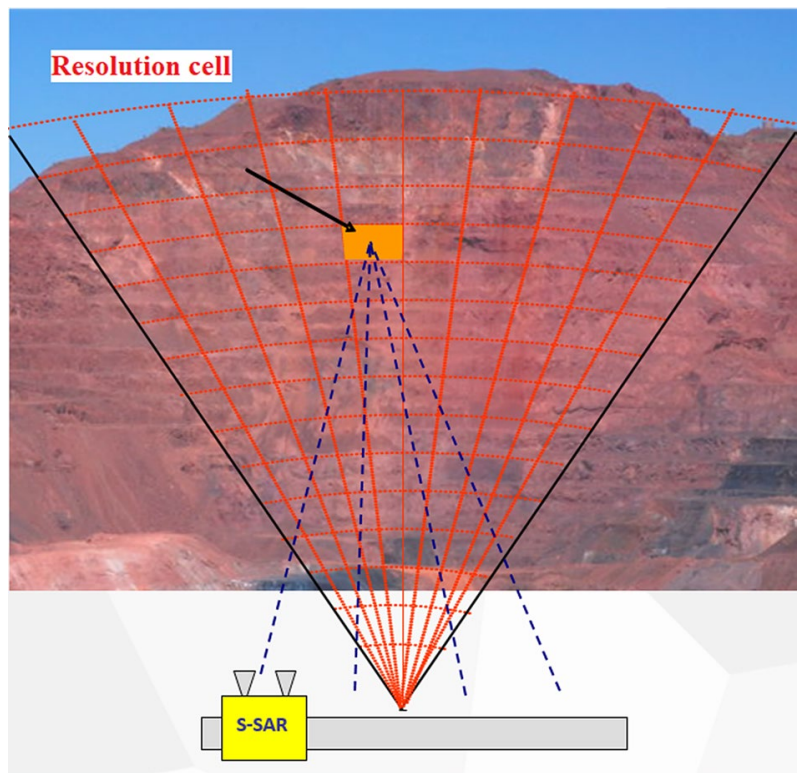

Fig. 8 Principle of S-SAR deformation measurement superposed within a few minutes after each scan to obtain the cumulative displacement cloud map of the latest monitoring area. Each pixel monitored by the radar has an $S-t$ curve, as shown in Fig. 1. The position of large deformation in the monitoring area can be judged by observing the displacement and deformation cloud image, however, the workload of tens of thousands or even hundreds of thousands of pixels is huge and the error is large, therefore, a method that can automatically identify the stage of accelerated deformation in a short time is needed.

\section{Automatic warning of areas at risk}

Based on the deformation data of each pixel collected by $\mathrm{S}$-SAR slope monitoring radar, the short-term and long-term velocity moving averages are solved in the time series as given by Formula 1 (Carlà et al. 2017a):

$\bar{v}=\frac{v_{t}+v_{t-1} \cdots \cdots+v_{t-n+1}}{n}$
Fig. 9 Slope S-SAR deformation cloud map

Fig. 10 The SMA curve crosses the LMA curve at a positive intersection $(\mathrm{OOA})$
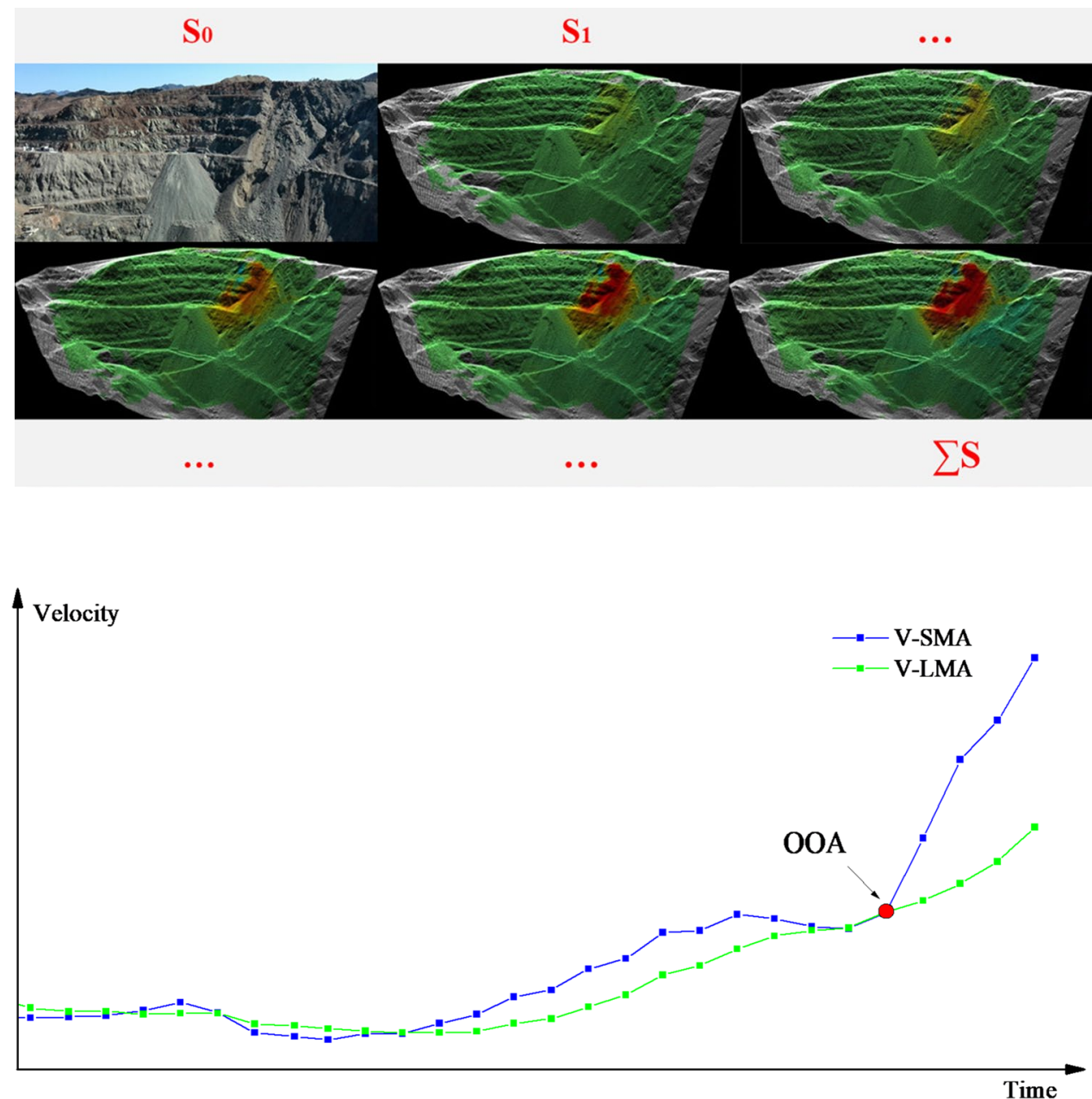
Fig. 11 The LMA curve crosses the SMA curve at a negative intersection (TOA)

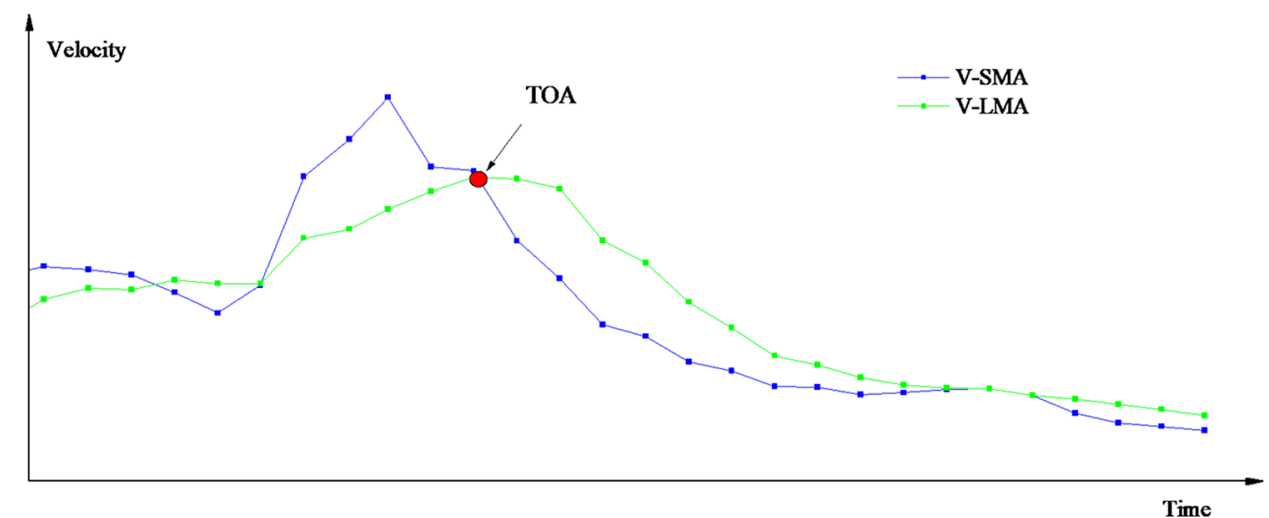

A short-term simple moving average (SMA), where $n=3$ is given by Formula 1. A long-term simple moving average (LMA), where $n=7$ is given by Formula 1 .

If the SMA and the LMA have a positive intersection, as shown in Fig. 10, the slope at this position begins to undergo accelerated deformation with an onset of acceleration point named OOA arising therewith.

If the SMA and the LMA have a negative intersection, as shown in Fig. 11, the slope at this position begins to undergo decelerating deformation, with a concomitant termination of acceleration point named TOA.

Formula 1 is used in the radar warning software to calculate the pixel points used in the monitoring area at intervals, and to determine the pixel points in the acceleration stage, and identify areas at risk. For monitored slopes, positive and negative intersections occur repeatedly with SMA and LMA due to factors such as external weather changes or manual excavation. When OOA occurs, it only indicates that the slope is accelerating and not reaching a dangerous level. Therefore, if the slope continues to accelerate to $\mathrm{N}$ times OOA after the occurrence of positive intersection, that is the value of $\mathrm{N}$ will be determined according to the specific mine situation, and the software will issue an early warning. When the warning software captures the last positive intersection before the landslide, the $S-t$ logarithm model can be used to predict the time to failure.

\section{Automatic warning of areas at risk}

By analyzing the landslide deformation monitoring data obtained in the laboratory, it is concluded that the inverse velocity and time can have concave, convex, or linear relationships, which can be expressed by Formula 2, and as shown in Fig. 12 (Fukuzono 1985). Experience shows that $a$ is between 1.5 and 2.2; here $a$ is almost equal to 2, making linear fitting of the inverse velocity-time data a simple and practical method for predicting the time to failure. The method is successfully applied to an open pit mine, and the

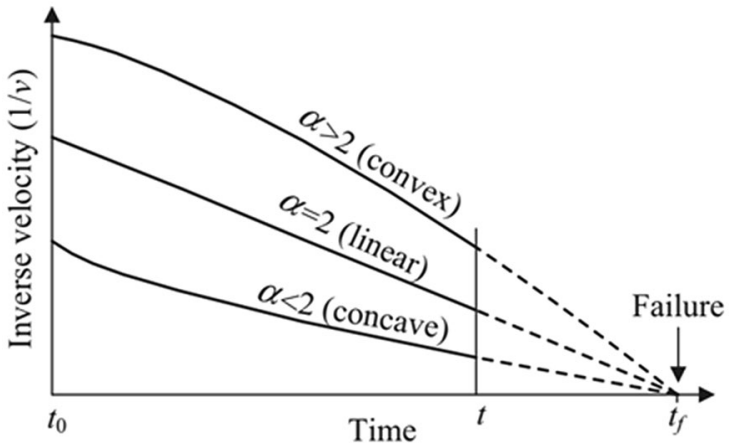

Fig. 12 Inverse-velocity versus time relationships preceding slope failure

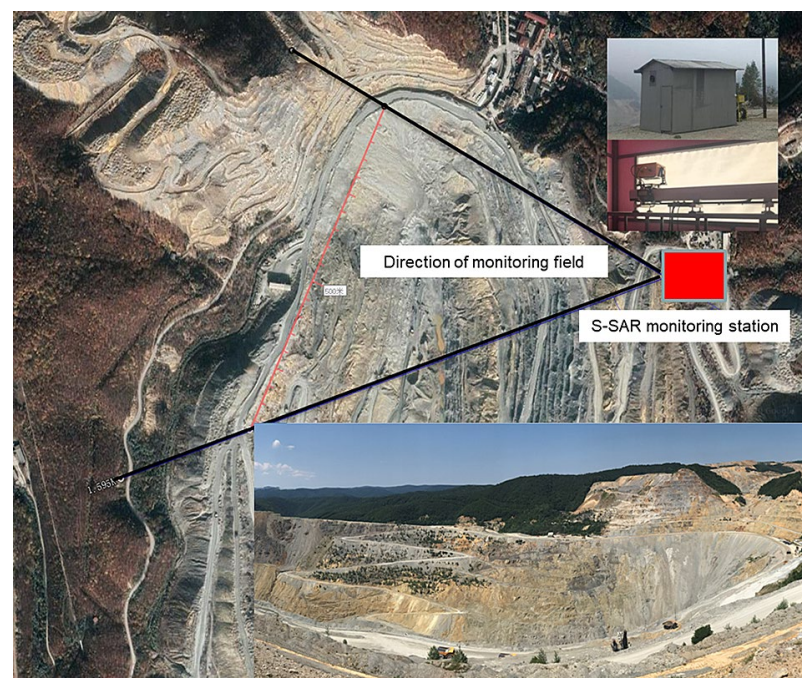

Fig. 13 S-SAR monitoring station in Majdanpek copper mine in Serbia

time of slope landslide is predicted by the intersection point of velocity reciprocal value and time trend line on the time axis (Rose and Hungr 2006). 
Fig. 14 S-SAR monitoring station in Majdanpek copper mine in Serbia. a 2019/12/9 2019/12/15 large-deformation areas appear; b 2019/12/9 2019/12/20 large-deformation areas apear; c 2019/12/92019/12/24: OOA appears
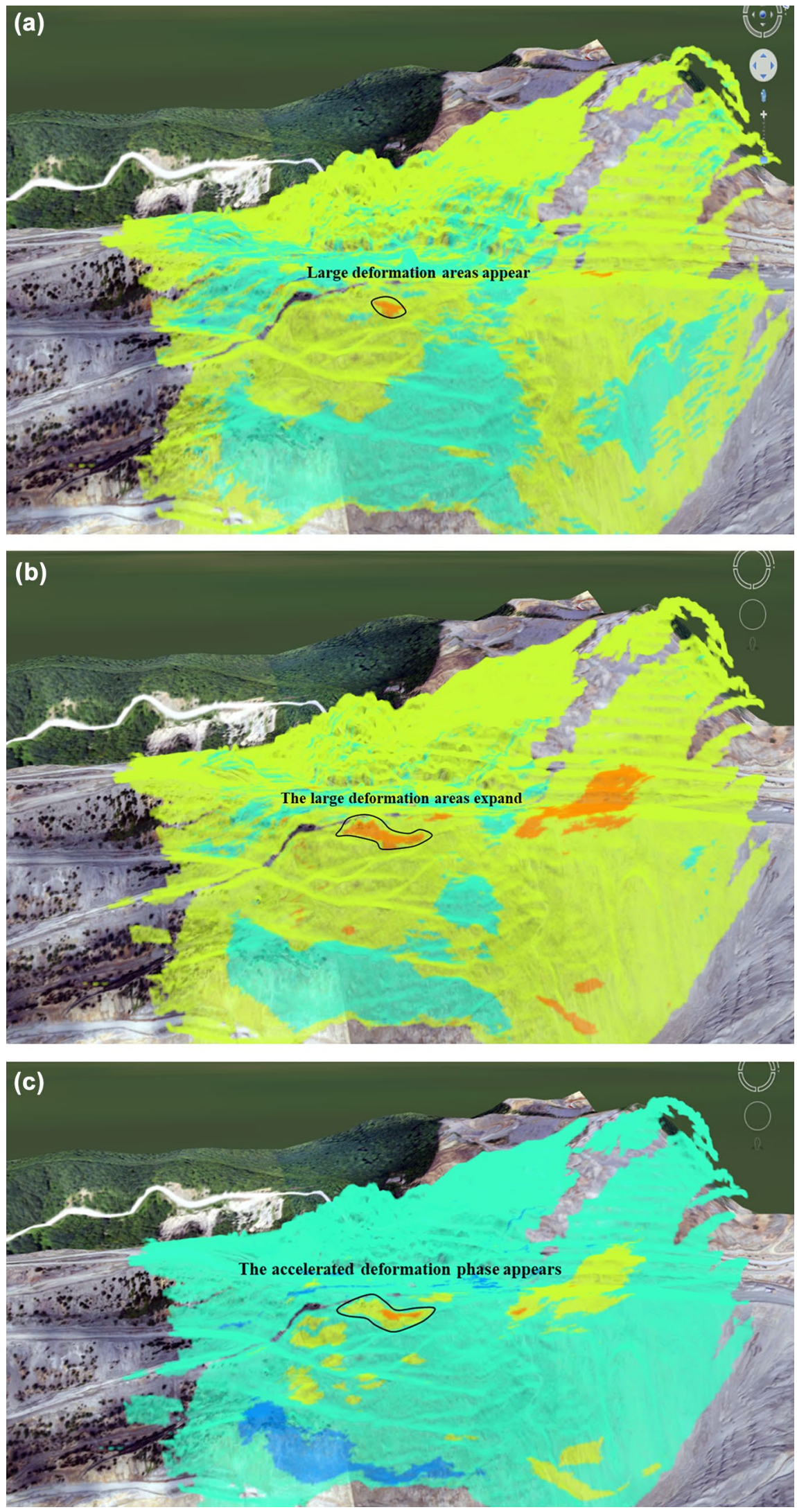


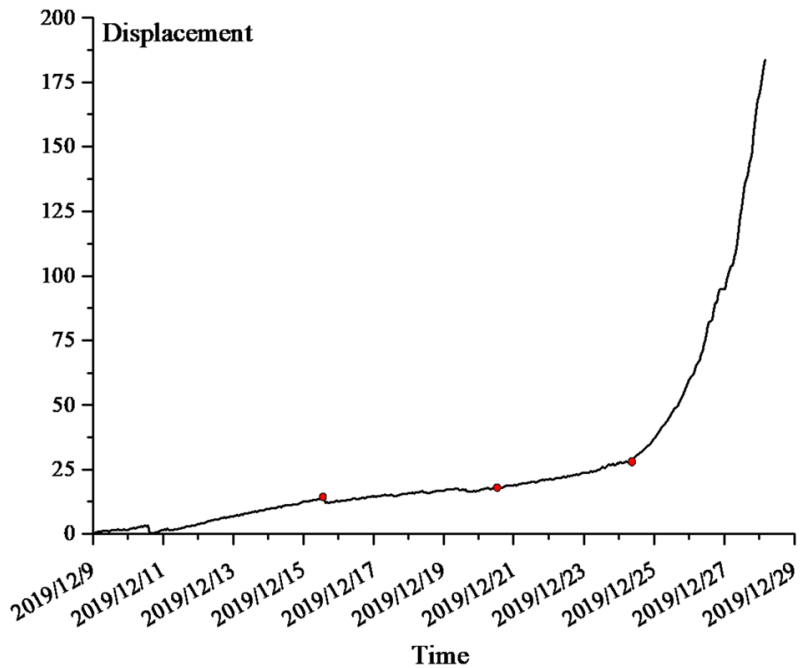

Fig. 15 Displacement-time curve in the deformation acceleration region

$\frac{1}{V}=[A(\alpha-1)]^{\frac{1}{\alpha-1}}\left(t_{f}-t\right)^{\frac{1}{\alpha-1}}$

where $V$ is the velocity. For $1<\alpha<2$, the resulting curve is concave; for $\alpha=2$, the resulting curve is linear; and for $\alpha>2$, the resulting curve is convex (Fukuzono 1985).

Many authors have improved the inverse velocity method. The linear fitting of the reciprocal of velocity to time should be the data after the OOA in the three stages of deformation. It is also noteworthy that if a TU point (trend update, that is significant change of acceleration trend) is identified, the linear fitting should be redone (Dick et al. 2015). The positive intersection point between the short-term moving average and the long-term moving average is used to demarcate the OOA (Carlà et al. 2017b). Identification of hazardous locations within the monitoring area by OOA and TOA based on this method is demonstrated above. In addition, the linear correlation between the inverse velocity and time is found to be weak after OOA in the initial stage (Bozzano et al. 2018). The traditional inverse velocity method is improved, and it can be used to predict the time of occurrence of the landslide when the deformation is slow (Zhou et al. 2020).

The inverse velocity method (INV) has become a widely used tool for predicting the onset of a landslide prediction due to its simple and practical characteristics. However, a landslide is a very complex natural phenomenon involving different inducing factors and rocks are complex heterogeneous materials, therefore, the inverse velocity method has certain limitations and can only be used for a slope which is unstable according to the theory of accelerated creep and is in a state of constant acceleration before the landslide. The hypothesis that the deformation velocity of a slope is infinite when it slides has not been proved.
Assuming the deformation velocity is infinite at the time of slope sliding, the point at which the reciprocal velocity intersects the linear trend line on the time-axis is the landslide time $T_{f}$. The linear fitting relationship between the reciprocal velocity and time of monitoring data before the onset of a landslide is given by Formula 3:

$\frac{1}{V}=-A \times\left(t-t_{s p}\right)+B$

where $A$ and $B$ are the deformation constants for the monitored slope, and $t_{S P}$ is the starting time of the data used in the prediction model. When $\frac{1}{V}=0$, the landslide time can be obtained, as shown in Formula 4:

$t_{f}=\frac{B}{A}+t_{S P}$

Formula 3 can be converted into Formula 5:

$V=\frac{1}{-A \times\left(t-t_{s p}\right)+B}$

Formula 6 is obtained upon integration of Formula 5:

$S=\frac{-\ln \left(-A \times\left(t-t_{s p}\right)+B\right)}{A}+C$

In the $S$ - $t$ curve, the OOA point last identified can be used as the starting point for the calculation of model prediction data. $A$ and $B$ are obtained using the logarithmic function model, and the predicted landslide onset can be calculated according to Formula 4. By updating the latest data collected by the slope monitoring radar, the correction parameters $A$ and $B$ approach the real landslide time point.

\section{The case for successful prediction of landslide in an open pit mine}

\section{Study area}

The S-SAR long-track slope deformation monitoring radar deployed in Majdanpek open-pit copper mine in Serbia is in the northeast corner of the mine and conducts real-time monitoring of the northwest slope of the mine. The average slope angle in the monitored area was about $65^{\circ}$. The data collection interval was set to $20 \mathrm{~min}$, and 72 groups of monitoring data were collected each day. The monitoring short distance was set to $800 \mathrm{~m}$ and the monitoring long distance was set to $1400 \mathrm{~m}$. The azimuth monitoring angle was about $50^{\circ}$, covering a slope length of about $1 \mathrm{~km}$. The slope monitoring radar station, the field slope optical imaging map, and the mining area satellite imaging map are illustrated in Fig. 13. 
(a)

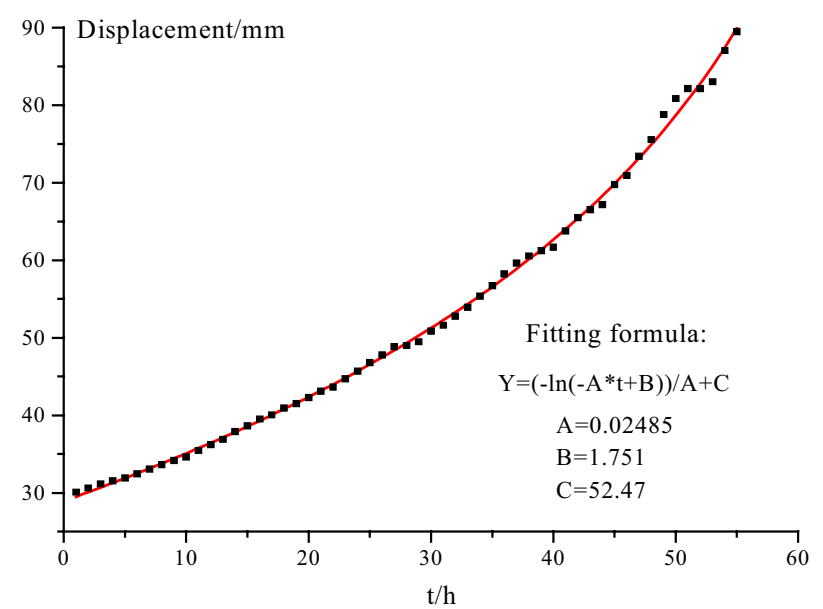

(c)

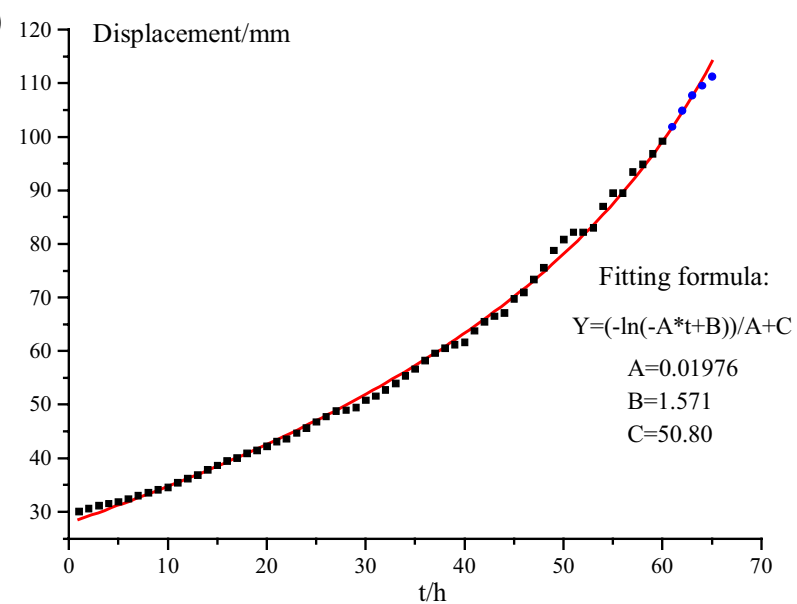

(e)

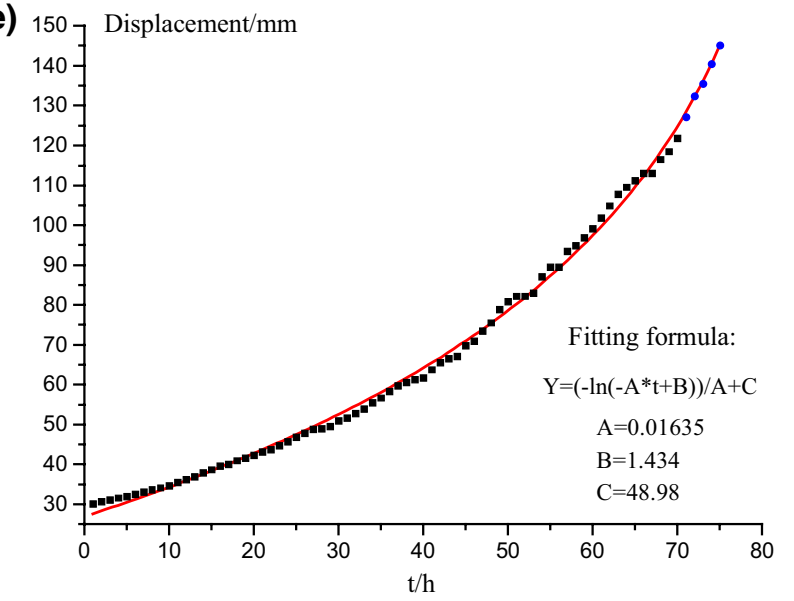

(b) $110 \mathrm{Z}$ Displacement $/ \mathrm{mm}$

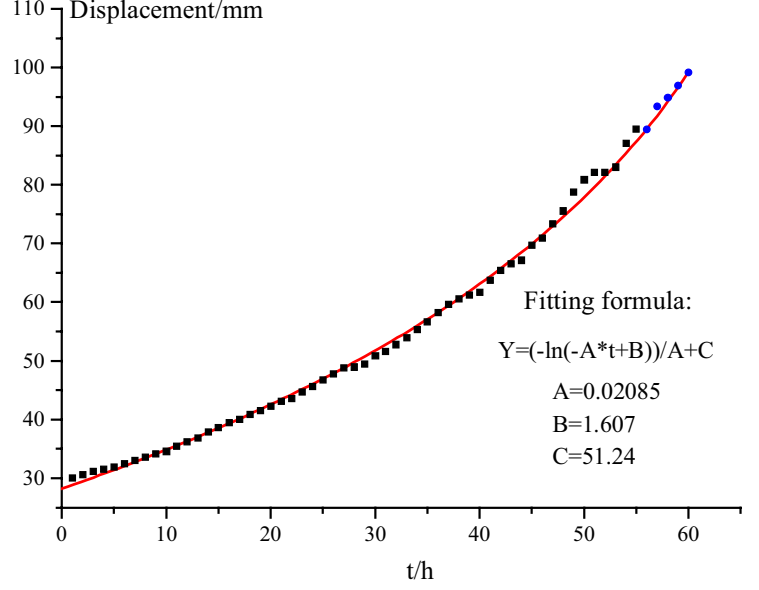

(d)

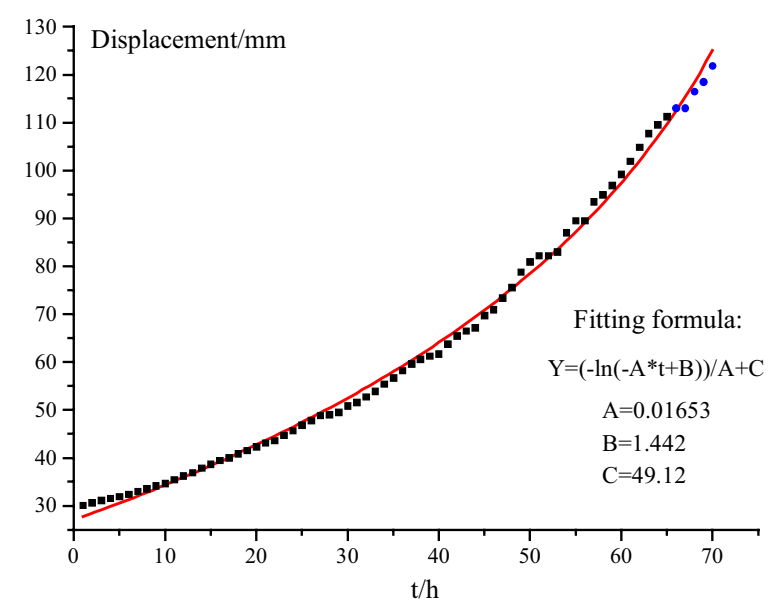

(f)

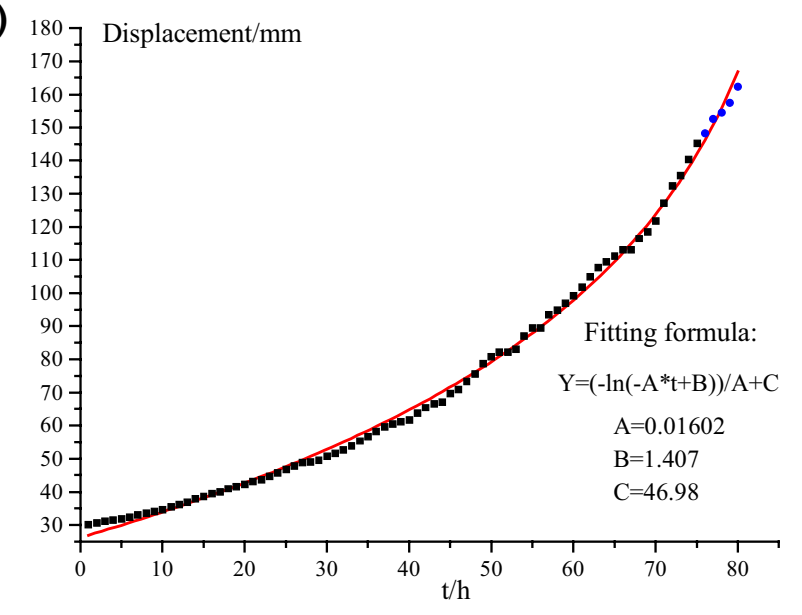

Fig. 16 The logarithmic prediction model is adopted to update and fit the data after OOA to predict the time to onset of the landslide

\section{Monitoring results}

Based on the analysis of Figs. 14 and 15, the following conclusions can be obtained: (a) In the 6 days from $2019 / 12 / 9$ to $2019 / 12 / 15$, the area subject to large deformation defined in Fig. 14a has an accumulated deformation of $23 \mathrm{~mm}$, and the area covers about $100 \mathrm{~m}^{2}$. Moreover, there is a strong linear relationship between displacement and time, so it can 
Table 1 Data updating: fitted values of parameters $A, B$, and $C$ and predicted landslide times

\begin{tabular}{llllll}
\hline Data after OOA & $A$ & $B$ & $C$ & $\begin{array}{l}\text { Predicted } \\
\text { failure time }\end{array}$ & $\begin{array}{l}\text { Actual } \\
\text { failure } \\
\text { time }\end{array}$ \\
\hline $0-55 \mathrm{~h}$ & 0.02485 & 1.751 & 52.47 & 70.46 & 15.46 \\
$0-60 \mathrm{~h}$ & 0.02085 & 1.607 & 51.24 & 77.07 & 17.07 \\
$0-65 \mathrm{~h}$ & 0.01976 & 1.571 & 50.80 & 79.50 & 14.50 \\
$0-70 \mathrm{~h}$ & 0.01653 & 1.442 & 49.12 & 87.24 & 17.24 \\
$0-75 \mathrm{~h}$ & 0.01635 & 1.434 & 48.98 & 87.71 & 12.71 \\
$0-80 \mathrm{~h}$ & 0.01602 & 1.407 & 46.98 & 87.83 & 7.83 \\
\hline
\end{tabular}

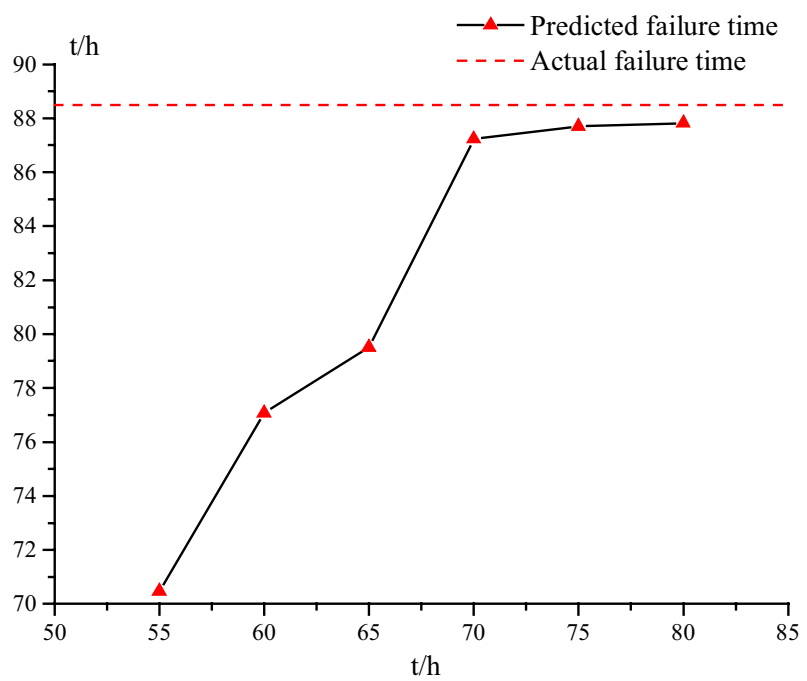

Fig. 17 Comparison of predicted and actual landslide times

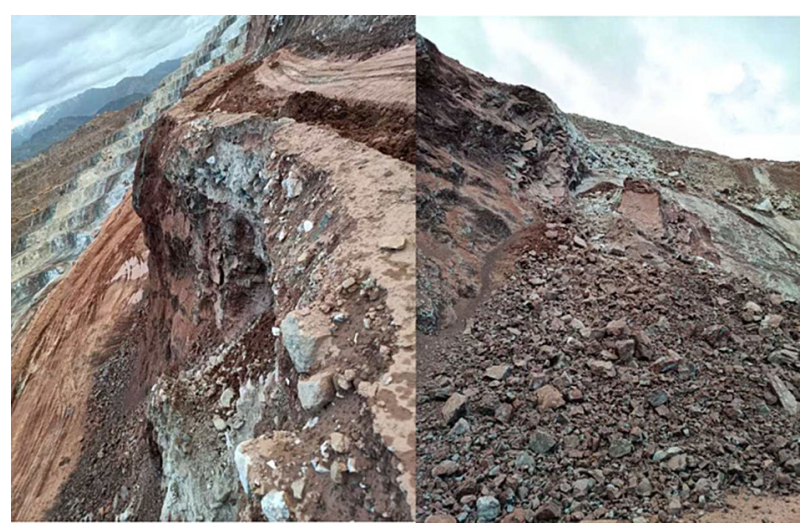

Fig. 18 Landslide in an area of large deformation

be judged that the slope has entered the second stage of the three stages of creep (i.e., the stage of uniform deformation). (b) During the period from 2019/12/16 to 2019/12/20, the slope deformation remained uniform, and the area subject to large deformation expanded from $100 \mathrm{~m}^{2}$ to 300 $\mathrm{m}^{2}$. Due to the influences of external factors such as construction operations nearby, the deformation data collected by radar sometimes appears to jump, but the overall relationship between displacement and time increases linearly.

(c) On 2019/12/24 at 12:00, the slope deformation began to accelerate into the third stage of creep deformation, and the OOA appeared: the S-SAR slope monitoring radar warning software captures OOA in the large deformation area, and the deformation continues to accelerate and trigger the slope radar warning software after OOA. The logarithmic function model is used to predict the time to onset of the landslide.

\section{Discussion}

It can be seen from the analysis of Fig. 16, Table 1, and Fig. 17 that the log function model was used to fit the monitoring data after OOA $(2019 / 12 / 24 / 12: 00$ is taken as time $t=0 \mathrm{~h}$ ), and the fitting was performed every $5 \mathrm{~h}$ before onset of sliding. A total of six data fitting calculations were performed to predict the landslide time. With the updating of monitoring data, the landslide time point predicted by the parameters of the prediction model tended to the actual landslide time of $88.5 \mathrm{~h}(2019 / 12 / 28 / 4: 00)$. At first, there was a large error between the predicted time and that at onset of the real landslide time due to the sparsity of the data points, and it was several hours earlier than the real landslide time. With the continuous updating of monitoring data, the predicted landslide time point in the data fitting after the third iteration stabilized to a value consistent with the real landslide time of onset. The position of the slip surface is shown in Fig. 18.

\section{Conclusion}

(1) In this paper, ground-based synthetic aperture radar is used to measure slope surface deformation and predict landslide time by studying slope deformation trend. It is not suitable for all areas, and it is only suitable for landslide with obvious acceleration deformation before sliding. This paper is using ground based observation data to predict the landslide, then do not need to tell about its accuracy.

(2) A landslide involves very complex processes: it is important to acquire detailed and accurate information about these processes. Traditional monitoring methods 
may be limited by the sampling rate and data accuracy, as well as the timeliness and locality of information, which cause a lack, or misunderstanding, thereof. Long-term continuous monitoring of the displacement of unstable slopes by ground-based radar enables us to establish high-resolution spatio-temporal data with an accuracy of $0.1 \mathrm{~mm}$ to describe the failure behaviors of landslides. Continuous high-precision measurements using ground-based radar have made significant contributions to landslide monitoring.

(3) The intersection points of the short-term moving average and the long-term moving average speed are OOA and TOA, respectively. The OOA point before the landslide is used to denote the onset of the acceleration of the deformation of the slope in the area monitored by radar. This method is simple, fast, and accurate: it can be applied with data acquisition software to realize automatic recognition and position identification of salient geotechnical features.

(4) The S-SAR slope radar has the advantages of high precision and rapid measurement: it can provide sufficient, accurate displacement and deformation monitoring data before the onset of a landslide and continuously provide the latest displacement data before the landslide to allow modification of the logarithmic model parameters, thus improving predicted times to onset of failure.

Author contributions All authors contributed to the study conception and design. Material preparation, data collection and analysis were performed by Y-hZ, H-tM, Z-xY. The first draft of the manuscript was written by $\mathrm{Y}-\mathrm{hZ}$ and all authors commented on previous versions of the manuscript. All authors read and approved the final manuscript.

Funding This research is supported by the National Key Research and Development Program of China (Grant Nos 2017YFC0804603 and 2018YFC0808402).

Availability of data and material The datasets used or analysed during the current study are available from the corresponding author on reasonable request.

\section{Declarations}

Conflict of interest We declare that we do not have any commercial or associative interest that represents a conflict of interest in connection with the work submitted.

Open Access This article is licensed under a Creative Commons Attribution 4.0 International License, which permits use, sharing, adaptation, distribution and reproduction in any medium or format, as long as you give appropriate credit to the original author(s) and the source, provide a link to the Creative Commons licence, and indicate if changes were made. The images or other third party material in this article are included in the article's Creative Commons licence, unless indicated otherwise in a credit line to the material. If material is not included in the article's Creative Commons licence and your intended use is not permitted by statutory regulation or exceeds the permitted use, you will need to obtain permission directly from the copyright holder. To view a copy of this licence, visit http://creativecommons.org/licenses/by/4.0/.

\section{References}

Borgeaud M, Noll J, Bellini A (1994) Multi-temporal comparisons of ERS-1 and JERS-1 SAR data for land applications. Geosci Remote Sens Symp, IGARSS 94(3):1603-1605

Bozzano F, Mazzanti P, Prestininzi A et al (2010) Research and development of advanced technologies for landslide hazard analysis in Italy. Land-Slides 7(3):381-385

Bozzano F, Mazzanti P, Moretto S (2018) Discussion to: 'Guidelines on the use of inverse velocity method as a tool for setting alarm thresholds and forecasting landslides and structure collapses.' Landslides 15(7):1437-1441

Brunner FK, Zobl F, Gassner G (2003) On the capability of GPS for landslide monitoring. Felsbau Rock Soil Eng 21(2):51-54

Carlà T, Intrieri E, Di Traglia F et al (2016) Guidelines on the use of inverse velocity method as a tool for setting alarm thresholds and forecast in gland slides and structure collapses. Landslides 14(2):517-534

Carlà T, Farina P, Intrieri E et al (2017a) On the monitoring and early-warning of brittle slope failures in hard rock masses: Examples from an open-pit mine. Eng Geol 228:71-81

Carlà T, Intrieri E, Di Traglia F et al (2017b) Guidelines on the use of inverse velocity method as a tool for setting alarm thresholds and forecasting landslides and structure collapses. Landslides 14(2):517-534

Carlà T, Farina P, Intrieri E et al (2018) Integration of ground-based radar and satellite InSAR data for the analysis of an unexpected slope failure in an open-pit mine. Eng Geol 235:39-52

Dick GJ, Eberhardt E, Cabrejo-Liévano AG et al (2015) Development of an early-warning time-of-failure analysis methodology for open-pit mine slopes utilizing ground-based slope stability radar monitoring data. Can Geotech J 52:515-529

Do TN, Wu JH, Lin HM (2017) Investigation of sloped surface subsidence during inclined seam extraction in a jointed rock mass using discontinuous deformation analysis. Int J Geomech 17(8):04017021

Do TN, Wu JH (2020) Simulating a mining-triggered rock avalanche using DDA: A case study in Nattai North. Australia. Eng Geol 264:105386

Fukuzono TA (1985) A new method for predicting the failure time of a slope. In: Proceedings of the fourth international conference and field workshop on landslides. Japan Landslide Society, Tokyo

Gariano SL, Guzzetti F (2016) Landslides in a changing climate. Earth Sci Rev 162:227-252

Ginting A, Stawski M, Widiadi R (2011) Geotechnical risk management and mitigation at Grasberg Open Pit, PT Freeport Indonesia. Proceedings of slope stability 2011: international symposium on rock slope stability in open pit mining and civil engineering. Canadian Rock Mechanics Association, Vancouver, $\mathrm{BC}$

Greco R, Giorgio M, Capparelli G et al (2013) Early warning of rainfall-induced landslides based on empirical mobility function predictor. Eng Geol 153:68-79

Haque U, Blum P, Da Silva PF et al (2016) Fatal landslides in Europe. Landslides 13(6):1545-1554 
Intrieri E, Gigli G, Mugnai F et al (2012) Design and implementation of a landslide early warning system. Eng Geol 147-148:124-136

Intrieri E, Gigli G, Casagli N et al (2013) Brief communication "landslide early warning system: toolbox and general concepts." Nat Hazards Earth Syst Sci 13:85-90

Kraus K, Jansa J, Kager H (1997) Photogrammetry advanced methods and applications, vol 2. Dummler, Bonn

Lacasse S, Nadim F (2009) Landslide risk assessment and mitigation strategy. Landslides - disaster risk reduction. Springer, Berlin Heidelberg, pp 31-61

Massonet D, Fiegl KL (1998) Radar Interferometry and its application to changes in the earth's surface. Rev Geophys 36(4):441-500

Pieraccini M, Casagli N, Luzi G et al (2003) Landslide monitoring by ground-based radar interferometry: a field test in Valdarno (Italy). Int J Remote Sens 24(6):1385-1391

Rose ND, Hungr O (2006) Forecasting potential rock slope failure in open pit mines using the inverse-velocity method. Int J Rock Mech Mining Sci 44(2):308-320

Saito M (1965) Forecasting time of occurrence of a slope failure. In: Proceedings of the sixth international conference on soil mechanics and foundation engineering Oxford, Pergamon pp 537-541.

Saito M (1969) Forecasting time of slope failure by tertiary cree. In: Proceedings of the 7th International Conference on Soil Mechanics and Foundation Engineering, Mexico City pp 677-683.
Srivastava SK, Lukowski TI, Gray RB et al (1996) RADARSAT: image quality management and performance results. Can Conf Electr Comput Eng 1:21-23

Tarchi D, Casagli N, Fanti R et al (2003) Landslide monitoring by using ground based SAR interferometry: an example of application to the Tessina landslide in Italy. Eng Geol 68:15-30

Teza G, Galgaro A, Zaltron N et al (2007) Terrestrial laser scanner to detect landslide displacement fields: a new approach. Int J Remote Sens 28(16):3425-3446

Ubydul H (2019) The human cost of global warming: deadly landslides and their triggers (1995-2014). Sci Total Environ 682:673-684

Wu JH, Lin WK, Hu HT (2018) Post-failure simulations of a large slope failure using 3DEC: the Hsien-du-shan slope. Eng Geol 242:92-107

Zhou XP, Liu LJ, Xu C (2020) A modified inverse-velocity method for predicting the failure time of landslides. Eng Geol 268:105521

Publisher's Note Springer Nature remains neutral with regard to jurisdictional claims in published maps and institutional affiliations. 